\title{
pro.posıções
}

$e$-ISSN 1980-6248

http://dx.doi.org/10.1590/1980-6248-2018-0063

ARTIGOS

\section{Reflexões sobre a educação do trabalhador a partir do pensamento de Simone Weil ${ }^{1}$}

\section{Reflections on the education of the worker of Simone Weil's thought}

Débora Mariz (i)

(i) Universidade Federal de Minas Gerais - UFMG, Belo Horizonte, MG, Brasil.

http://orcid.org/0000-0001-9326-0511, deboramariz@gmail.com.

\begin{abstract}
Resumo:
A filósofa francesa Simone Weil (1909-1943) buscou compreender o estatuto do trabalho na vida humana, bem como as formas de opressão operária vigentes em sua época. Ela propôs uma ressignificação do trabalho, visando à liberdade e à dignidade humana. Embora o trabalho seja um tema frequentemente referido nos artigos dedicados a essa pensadora, poucos dentre eles enfatizam a viabilidade de sua proposta na atualidade. Nesse sentido, este artigo visa articular o pensamento weiliano a três teóricos do século XXI. Analisamos as propostas da psicologia do trabalho expressas por Yves Clot e Christophe Dejours. Também analisamos o modelo fenomenológico proposto por Hubert Dreyfus para compreender de que maneira se desenvolvem as habilidades e de que modo elas se expressam no corpo do expert. Estabelecemos, assim, possíveis diálogos com o pensamento weiliano a partir dos conceitos centrais presentes em sua proposta de educação do trabalhador, buscando transpor esses conceitos para nossa realidade.

Palavras-chave: Simone Weil, trabalho, educação, corpo
\end{abstract}

${ }^{1}$ Normalização, preparação e revisão textual: Aline Maya (Tikinet) - revisao@tikinet.com.br 


\title{
pro.posıções \\ $e$-ISSN 1980-6248
}

http://dx.doi.org/10.1590/1980-6248-2018-0063

\begin{abstract}
:
The French philosopher Simone Weil (1909-1943) sought to understand the status of work in human life, as well as the forms of worker oppression in its time. She proposed a re-signification of work, aiming at freedom and human dignity. Although the work is a theme frequently mentioned in the articles dedicated to this thinker, few of them emphasize the feasibility of its proposal at the present time. In this sense, this article aims to articulate the Weil's thought to three theorists of the 21 th century. We analyze the proposals of the psychology of the work expressed by Yves Clot and Christophe Dejours. We also analyze the phenomenological model proposed by Hubert Dreyfus to understand how skills are developed and how they express themselves in the expert's body. We will thus establish possible dialogues with Weil's thought, based on the central concepts present in his proposal of education of the worker, seeking to transpose these concepts into our reality.
\end{abstract}

Keywords: Simone Weil, work, education, body

\section{Introdução}

Simone Weil (1909-1943) foi uma importante pensadora do século XX. Ela viveu em um contexto marcado por intensos movimentos sociais de luta por melhores condições de trabalho para os operários, bem como pelo engajamento de intelectuais para promover a formação educacional dos trabalhadores. Teve instrução clássica rigorosa, tornando-se leitora arguta da tradição grega e dos filósofos modernos (Descartes e Kant, em particular); foi tanto discípula quanto crítica de Marx e dos marxistas. Participou das lutas sindicais, ministrou cursos educacionais para os trabalhadores em Saint-Étienne, além de ter lecionado filosofia em escolas públicas de nível médio para filhos de operários. Lutou na Guerra Civil Espanhola ao lado dos republicanos, junto à coluna Durruti. Experienciou tanto o trabalho de fábrica, como operária metalúrgica da Renault, quanto o trabalho agrícola em Saint-Marcel-d'Ardèche e em SaintJulien-de-Peyrolas. Todas essas experiências remetem ao profundo desejo weiliano de "ter um contato direto com a vida", que ela entendia como aquilo que ultrapassa a mera especulação filosófica, unindo teoria (ciência) e prática (trabalho), ou pensamento e ação. Engajou-se, por fim, na Resistência Francesa em Londres, onde veio a falecer. Em sua breve vida, compôs um conjunto de 16 volumes de escritos, ainda em curso de publicação. 


\section{pro.posıções \\ $e$-ISSN 1980-6248}

O trabalho no pensamento weiliano é um tema frequentemente referido nos artigos dedicados a essa pensadora; contudo, poucos dentre eles enfatizam a viabilidade de sua proposta na atualidade. Como seria possível essa proposta weiliana de ressignificação do trabalho em nossa modernidade? Eis o problema norteador deste texto.

\section{O termo 'trabalho' para Simone Weil}

Antes de nos debruçarmos sobre essa questão, faz-se necessário compreender em que sentido Weil utiliza o termo "trabalho". A esse respeito, encontramos três usos recorrentes desse termo nos escritos weilianos: (i) o trabalho como ação humana transformadora do mundo; (ii) o trabalho como atividade remunerada realizada pelo ser humano no contexto capitalista, especificamente o trabalho operário e agrícola; e (iii) o trabalho como métier, tendo como modelo recorrente aquele realizado pelo marinheiro. Esses usos não são excludentes, mas gostaríamos de ressaltar, neste momento, a especificidade de cada um deles.

i. Compreendido em um sentido amplo, o trabalho é, para nossa pensadora, a ação por excelência do ser humano, aquela que o inscreve no mundo, permitindo a transformação de si mesmo e do próprio exterior. Nesse sentido, a proposição weiliana de trabalho muito se aproxima daquela proferida por Marx. Nessa açãotrabalho estão contidas desde as atividades cotidianas, como regar as plantas ou preparar uma refeição, até as atividades intelectuais, como a da escrita de um texto. O elemento central dessa concepção de trabalho é a relação do corpo com alguma matéria a ser transformada, que lhe é exterior e antagonista. Decorre dessa concepção que, se toda ação transformadora do ser humano no mundo é trabalho, e esta promove um contato genuíno do ser humano com o mundo, em que há unidade entre pensamento e ação, todo ser humano deveria realizá-lo, independentemente de seu status social e educacional.

ii. Como sinônimo de ação remunerada, o trabalho apresenta-se como uma preocupação central no pensamento weiliano, visto ser ele fonte de alienação e opressão moralmente degradante do trabalhador. A crítica weiliana recai fortemente sobre o modo como a ciência e a técnica determinaram a cadência do corpo do trabalhador, bem como interferiram na aprendizagem da percepção que os homens 


\section{pro.posições \\ $e$-ISSN 1980-6248}

http://dx.doi.org/10.1590/1980-6248-2018-0063

possuem do mundo. Além disso, a organização social do trabalho impõe um sentido deturpado à ação humana sobre o mundo e destitui do trabalhador a consciência da lei do trabalho, também denominada por ela de "lei do mundo", na qual todos nós estamos inscritos e onde "a geometria é a única física geral” (Weil, 1988a, p. 135). Resgatar essa consciência perpassa um novo modo de agir ou um novo sentido do trabalho, chamado por Weil de espiritualidade no trabalho, que se perdeu em nossa modernidade. Para tanto, o corpo terá um papel fundamental, visto seu caráter mediador da relação homem-mundo, que deverá ser marcado não mais pela imposição de uma cadência, mas pelo resgate de um ritmo próprio a essa mediação entre o corpo vivo e o mundo.

iii. Enquanto métier, o trabalho seria o modelo ideal de ação humana no mundo, aquele que conseguiria reunir em uma só ação: o trabalho, a arte e a ciência, o que talvez pudéssemos compreender como a busca da unidade entre pensamento, ação e contemplação. Podemos dizer que Weil buscou resgatar a unidade desses três âmbitos do conhecimento humano, articulando-os no modelo do trabalho físico. Vale ressaltar que esses três âmbitos foram formalmente separados na Antiguidade grega por Aristóteles e aceitos na tradição filosófica posterior, a saber, os âmbitos da atividade contemplativa (theoría), da atividade ético-política (práxis) e da atividade produtiva (poíesis). Nesse sentido, Weil denuncia a cisão entre atividades de vida diária, trabalho e lazer; entre a ação de autossubsistência, aquela para obtenção de dinheiro e aquela para satisfação pessoal; entre pensamento, ação e contemplação; bem como entre estudo e trabalho; trabalho intelectual e trabalho manual. A pensadora francesa, ao propor a superação dessa cisão em sua filosofia do trabalho, valoriza o agir (práxis), tendo por fim a dignidade do trabalho, e não o produto; mas esse agir possui motivações impessoais, sendo determinado pela necessidade e inscrito em uma ordem que lhe é exterior e pertencente ao domínio da poiesis (Chenavier, 1998, p. 190). Sendo assim, há um perfeito acordo entre a atividade metódica do corpo e do pensamento e a ordem da necessidade sobre a qual opera essa atividade. $O$ trabalho assim entendido é concomitantemente o modo fundamental de o ser humano agir, contemplar e criar em sua relação com o mundo e com os outros. 


\section{pro.posıções \\ $e$-ISSN 1980-6248}

Considerando esses três usos do termo trabalho, buscaremos compreender de que maneira Weil propõe a humanização do trabalho dentro do sistema capitalista e em que sentido essa proposta poderá ser transposta em nossa modernidade. A esse respeito, a pensadora afirma de modo contundente:

Um operário que experimenta sem cessar a lei do trabalho pode conhecer bem mais acerca de si mesmo e do mundo que o matemático que estudou a geometria sem saber que ela é uma física, que o físico que não dá pleno valor às hipóteses geométricas. O operário pode sair da caverna, os membros da Academia das ciências podem se mover entre as sombras. (Weil, 1988a, pp. 136-137)

Mas por meio de quais modificações poderiam o operário e o cientista sair da caverna? Será efetivamente possível a unidade pensamento-ação-contemplação em nossa modernidade? E poderíamos ainda compreender a nossa civilização, marcada pela prestação de serviços e pela virtualidade, como uma civilização do trabalho? Se considerarmos todo o desenvolvimento técnico em curso desde a década de 1930, período em que viveu Simone Weil, perceberemos que as máquinas flexíveis ${ }^{2}$ já foram criadas e substituíram em grande parte os trabalhadores não qualificados nas fábricas. Contudo, se analisarmos os dados referentes ao trabalho na atualidade, fica evidente que o adoecimento do trabalhador, decorrente de acidentes de trabalho que o levam ao afastamento por invalidez, ainda se faz presente - e de maneira crescente - no Brasil ${ }^{3}$, a despeito de toda ergonomia e de todas as medidas de segurança implementadas nos postos de trabalho.

Apesar de a demanda atual do mercado de trabalho concentrar-se no setor de prestação de serviços, e não na indústria, distintamente da época na qual viveu Simone Weil, o problema do sentido do trabalho ainda se coloca de maneira pungente. Isso porque a mecanização do trabalho e a cisão entre pensar e trabalhar adquiriram outras formas, não menos opressoras, como o cumprimento de metas, a padronização de condutas e o desconhecimento de todo o

\footnotetext{
${ }^{2}$ Uma solução weiliana para essa ruptura entre o pensar e o agir no trabalho consiste em propor mudanças em sua organização que incluam máquinas automáticas flexíveis, ou seja, que possuam certa capacidade de adaptação ao corpo do trabalhador e à execução de diversas tarefas, e não o contrário (Weil, 1964, p. 259). Como bem observou Robert Chenavier, a proposta weiliana de desenvolvimento de máquinas automáticas flexíveis assemelha-se à proposta de Gilbert Simondon, que diz: "Pour réduire l'aliénation, il faudrait ramener à l'unité dans l'activité technique l'aspect de travail, de peine, d'application concrète impliquant usage du corps, et l'interaction des fonctionnements" (Simondon, 1969, pp. 251-252 citado por Chenavier, 2001, p. 432).

${ }^{3}$ No Brasil, percebemos que as ações governamentais para melhoria da saúde do trabalhador, visando a redução dos acidentes de trabalho, não obtiveram ainda o êxito esperado. Segundo dados da Previdência Social, em 2005 foram registrados 499,6 mil acidentes de trabalho urbanos, e esse número foi crescente nos anos posteriores, chegando a 717,9 mil em 2013 (Brasil, n.d.).
} 


\section{pro.posıções \\ $e$-ISSN 1980-6248}

processo de trabalho, ilustrado, por exemplo, no setor de telemarketing ${ }^{4}$. Ainda se faz presente na atualidade a alienação no trabalho, bem como as consequências funestas da civilização do trabalho: a marca do ilimitado na desproporção, no desequilíbrio e na desmedida do agir humano. A proposta weiliana de uma civilização do trabalho ultrapassa o âmbito das relações formais de produção, consistindo em uma nova maneira de o homem agir sobre o mundo. Assim compreendido, o trabalho transpõe a dimensão econômica e social, sem negá-las, adquirindo um sentido propriamente antropológico-filosófico.

\section{Marx e Simone Weil: aproximações e distanciamentos}

A proposta weiliana consiste em uma civilização do trabalho - não no sentido capitalista ou no sentido socialista vivenciado na antiga URSS (atual Rússia) desde o plano quinquenal, pois essas experiências valorizaram o produto do trabalho, e não o trabalhador. Sua proposta é a do trabalho compreendido como o ato humano por excelência, sendo o próprio centro da cultura, de modo que não pode mais ser visto como "um meio de escapar da vida real", mas deve ser tomado como aquilo que faz os homens livres (Weil, 1991, p. 85).

Para tanto, é fundamental uma educação operária como método de libertar da ignorância um povo amansado pela cultura de massa. E essa educação consiste não apenas na formação teórica dos trabalhadores, mas inclui um modo novo de execução do próprio trabalho, em que há um direcionamento do olhar para a verdade - tal como dizia Platão na alegoria da caverna. A despeito de Marx, Weil compreende a revolução como a união entre trabalho manual e intelectual, "fazendo os trabalhadores sentirem, tanto quanto possível, a íntima relação que existe entre o trabalho e os conhecimentos teóricos de toda espécie adquiridos pela humanidade

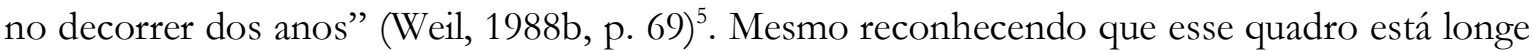
das condições reais da vida humana, mais longe do que a ficção da "idade de ouro", a pensadora

\footnotetext{
${ }^{4}$ Também na psicopatologia do trabalho foi diagnosticada, em 1970, a síndrome de burnout, relacionada a períodos prolongados de estresse e frustração no trabalho, gerando exaustão emocional, esgotamento, intolerância, irritabilidade no e fora do trabalho, frieza e indiferença, distanciamento emocional e redução da realização profissional e pessoal (França \& Rodrigues, 2005).

5 Ver Rolf Kühn (2003, p. 58). Weil não apenas critica Marx, mas busca revisar o próprio conceito de revolução, permanecendo fiel à sua convicção filosófica de nada aceitar sem antes submeter o pensamento a um julgamento justo.
} 


\section{pro.posıções \\ $e$-ISSN 1980-6248}

enfatiza a importância de esse ideal, enquanto ideal, ser o ponto de referência para a análise das formas sociais reais.

A ressignificação do trabalho proposta pela filósofa o torna não apenas uma ação humana no mundo, mas objeto de contemplação do próprio mundo. Weil escreve na introdução de seu Diário da fábrica: "Não somente que o homem saiba o que ele faz - mas se possível que ele perceba o uso - que ele perceba a natureza modificada por ele. Que para cada um seu próprio trabalho seja um objeto de contemplação" (Weil, 1991, p. 71). Se o trabalhador estiver de tal forma unido às ferramentas do seu trabalho, este seria equivalente à arte.

Para Simone Weil, o mal essencial da humanidade reside na substituição dos fins pelos meios na busca pelo poder, pois o desejo de poder é apenas a procura de meios de ação que ultrapassam a força de um indivíduo. Para a autora, as relações de dominação e submissão constituem um desequilíbrio sem remédio e expresso tanto na vida privada - quando o amor procura subordinar seu objeto ou subordinar-se - quanto na vida pública - pela divisão do trabalho que exclui a igualdade, condenando a vida social à luta pelo poder.

Ao empreender a análise da noção de força, Simone Weil se distancia de Marx por não considerar a sociedade como uma matéria na qual as forças se opõem e não conceber que dessa oposição poderia nascer a justiça. Ao contrário, ela diz que da opressão só nasce a submissão moralmente degradante do trabalhador, e não a revolução, tal como pretendia Marx. Nesse sentido, a filósofa afirma que, ao negar a transcendência (o Bem), Marx se ateve somente à necessidade presente no mundo e acreditou que dela adviria a justiça. Weil compreende que dessa oposição de forças sociais só poderá nascer o fanatismo e a idolatria, mas nunca a justiça, por entendê-la como um princípio absoluto que não pode ser colocado nas coisas humanas, e sim no plano sobrenatural. Além disso, ela diz que a revolução no sentido marxista levaria à emancipação das forças produtivas, e não à emancipação do homem. Assim, a justiça só será efetivamente realizada na mediação entre a necessidade e o bem. Mas de que maneira, então, se daria esta mediação? E ela seria suficiente para o homem sair dessa dominação?

Se culturalmente ocorreu uma cisão entre pensamento e ação - sendo o pensar executado por técnicos qualificados e cientistas, e o agir realizado pelos operários -, socialmente o imperativo econômico impôs um ritmo desenfreado à produção e transformou o trabalho numa repetição de gestos sem sentido para o trabalhador, que entrou num ciclo de trabalhar para comer e comer para trabalhar. 


\section{pro.posıções \\ $e$-ISSN 1980-6248}

Considerando essa cisão corpo/alma e pensamento/ação na vida humana, Simone Weil compreende que os homens tendem a buscar compensações para suportar o vazio de sua existência, seja a conquista de uma melhor condição de vida social (riqueza ou herança para os filhos), seja a busca de prazeres fúteis, ditados pela indústria cultural ou pela crença em uma civilização do lazer. Nenhuma dessas compensações, contudo, é aceita pela pensadora, que compreende o corpo como um intermediário (metax $u$ ) para que o homem estabeleça uma conexão entre os diversos planos da realidade e remedeie a cisão existente entre a vida profana e a espiritual, ou entre o pensar e o agir, própria do trabalho moderno.

Para superar essa cisão, Simone Weil propõe um resgate daquilo que é propriamente do ser humano, ou seja, sua capacidade de pensar e agir e a sociedade da qual ele depende, que precisa dessa unidade pensamento-ação. Apesar de o homem na atualidade estar sujeito à busca desmedida de poder e à submissão a outros homens, "nada no mundo pode obrigar um homem a exercer sua capacidade de pensamento nem lhe retirar o controle de seu próprio pensamento" (Weil, 1991, p. 85).

$\mathrm{Na}$ vida social contemporânea, o pensamento está reduzido a um papel subalterno, e é como se a função de controlar fosse transferida do pensamento para as coisas, por exemplo, na utilização da propaganda para determinar padrões de consumo ou certo modo de vida. Também o poder do Estado é exercido em todos os domínios, até mesmo no pensamento, como visto nas formas totalitárias de organização social. Inclusive, explica a filósofa francesa, "é a ausência de pensamento livre que torna possível impor pela força doutrinas oficiais inteiramente desprovidas de significado" (Weil, 1991, p. 104).

Como bem observou Sparling (2012, p. 92), apesar de essas considerações da condição operária remeterem ao pensamento de Marx, Weil critica erroneamente esse pensador ao atribuir-lhe "um desejo tecnofílico de escapar do trabalho". Entretanto, suas críticas foram acertadas quando remeteu à pouca atenção dada por Marx à associação entre ciência e tecnologia como um modo de reforçar a alienação social, além de ele não perceber que a abolição da propriedade burguesa não eliminaria a desigualdade social, nem que a ciência moderna restringiria o conhecimento aos especialistas, levando as pessoas à crença acrítica na autoridade intelectual desses detentores do saber. Ainda de acordo com Sparling (2012), enquanto para Marx a obra é produto do reconhecimento do fazer humano, para Weil a obra é secundária, 


\section{pro.posıções \\ $e$-ISSN 1980-6248}

http://dx.doi.org/10.1590/1980-6248-2018-0063

pois o mais importante no trabalho é a própria realização da ação que permite a contemplação do mundo.

\section{A concepção weiliana de educação do trabalhador na atualidade}

Em uma conferência proferida em 2014, Chenavier se pergunta se Simone Weil poderia auxiliar a pensar novas perspectivas para os modelos de administração e de gestão do trabalho atual. Mesmo reconhecendo que ela não poderia prever as novas formas de trabalho decorrentes da racionalização do sistema capitalista, o intérprete sustenta que a fonte primordial dessa racionalização, denunciada por Simone Weil já na década de 1930, permanece a mesma na atualidade, pois continua a forçar os trabalhadores a dar o máximo de si para a empresa. Nesse sentido, o capitalismo ainda impõe uma forma de leitura unidimensional do mundo, reduzindo tudo ao valor de mercado.

Vale mencionar ainda a tese de Bernardo Svartman, defendida no Brasil em 2010, que apresenta uma pesquisa de campo na área da psicologia social em que foram realizadas entrevistas com operários de fábricas metalúrgicas da região do ABC Paulista, tendo como eixo teórico o pensamento de Simone Weil. Esse pesquisador defende a tese de que "a organização capitalista do trabalho representa um golpe contra a necessidade de enraizamento e está necessariamente ligada a uma situação de humilhação social" (Svartman, 2010, p. 5). Apesar dessa conclusão desoladora, não nos parece inviável aplicar alguns pressupostos da proposta weiliana de enraizamento, tal como aquele da atenção e do ritmo, se considerarmos a diversidade de relações trabalhistas que se fazem presentes na atualidade. Talvez no contexto atual da fábrica, como na metalurgia, tenhamos de fato que reconhecer a extrema dificuldade de enraizamento operário, mas isso não nos parece ser uma condição estrutural e definitiva de todo trabalho capitalista, visto que ele se mostra de maneiras diversas se compreendido em uma sociedade de "plena atividade".

Considerando essas pesquisas, percebemos que, se por um lado as denúncias de Simone Weil acerca da opressão social no trabalho ainda se fazem presentes, há uma dificuldade de conciliar seu pensamento com o modo como o trabalho se configurou na atualidade. É preciso reconhecer essa dificuldade, considerando as transformações sociais decorrentes dessa nova organização do trabalho, pois são bem distintas daquelas vivenciadas pela filósofa no contexto 


\section{pro.posıções \\ $e$-ISSN 1980-6248}

da fábrica. Contudo, não nos parece plausível eliminar suas propostas de ressignificação do trabalho por se situarem no contexto trabalhista da década de 1930 na França e por esse já não ser mais o modelo hegemônico na atualidade.

Três critérios foram escolhidos para a definição de nossos interlocutores, que consistiu na seleção de: (i) autores que defendem a tese da centralidade do trabalho na atualidade, contrariamente à tese defendida por alguns pensadores contemporâneos sobre o fim desse protagonismo. Este critério deve-se à nossa posição de que o trabalho se faz presente em nossa atualidade e possui ainda uma função importante na organização social e na autoconstrução do ser humano. (ii) Também procuramos autores que defendem, no século XXI, o resgate da saúde do trabalhador, levando em conta a própria atividade realizada por ele, isto é, que buscam em alguma medida ressignificar a atividade desempenhada pelo indivíduo considerando seus postos de trabalho, sua ação e seus gestos corporais. Esse critério tem como referência a concepção de que a dignidade do ser humano pode ser encontrada na própria atividade do trabalhador. E, por fim, (iii) selecionamos textos que fazem referência à importância da significação do corpo na atualidade, considerando os desafios sociais diante de uma sociedade marcada pela virtualidade. Estabeleceremos, assim, possíveis diálogos com o pensamento weiliano a partir dos conceitos centrais presentes em sua proposta de ressignificação do trabalho, buscando transpor estes conceitos para nossa realidade.

Considerando esses três critérios, encontramos na psicologia do trabalho dois interlocutores para nossa pesquisa: Yves $\mathrm{Clot}^{6}$ e Christophe Dejours ${ }^{7}$. Esses pesquisadores desenvolvem, há algumas décadas, vários estudos de campo com trabalhadores de empresas francesas, o que talvez possibilite uma aproximação do pensamento weiliano à realidade do trabalho contemporâneo, pelo menos no contexto francês. Em suas obras, os dois pensadores citam brevemente a obra $A$ condição operária, de Simone Weil, fazendo referência à interdição de pensar no trabalho como forma de não sofrer para suportar, desse modo, a submissão

\footnotetext{
${ }^{6}$ Yves Clot é psicólogo do trabalho e professor titular de psicologia social do Conservatoire National des Arts et Métiers de Paris (CNAM). Possui formação em filosofia, defendendo em sua tese doutoral uma análise do trabalho inspirada em Ivar Oddone, na qual propõe a necessidade de transformar a comunidade científica, de modo a "deixar ao trabalhador a possibilidade de ele mesmo afetar e controlar a psicologia do trabalho mediante formas de cooperação entre eles.... O ponto de partida da minha entrada na disciplina da psicologia do trabalho seria, então, propor uma nova forma de atividade comum no mundo do trabalho, com os trabalhadores" (Clot, 2006, p. 100).

7 Christophe Dejours é doutor em medicina e especialista em medicina do trabalho. Atua como psiquiatria e psicanalista, é professor titular no CNAM e dirige o Laboratório de Psicologia do Trabalho e da Ação dessa instituição.
} 


\section{pro.posıções \\ $e$-ISSN 1980-6248}

degradante às condições de trabalho (Clot, 2010a, p. 93; Dejours \& Gernet, 2012, p. 15). Contudo, esses autores não fazem referência à proposta weiliana de ressignificação do trabalho.

Outro interlocutor escolhido foi o filósofo contemporâneo Hubert Dreyfus, que propõe um modelo fenomenológico para compreender a aquisição de habilidades no qual o corpo tem papel fundamental. Acreditamos que as análises de Dreyfus contribuem para nossa defesa da possibilidade de vivenciar a proposta weiliana no trabalho atual se considerarmos o conceito de leitura ${ }^{8}$ cunhado pela pensadora em associação aos estágios de aquisição de habilidades enumerados por Hubert Dreyfus e Stuart Dreyfus (2005).

Yves Clot e Christophe Dejours reafirmam, em suas obras, sua oposição à tese do fim do trabalho e defendem a centralidade deste na vida humana, não podendo ser entendido como mera ocupação entre outras, por ser a atividade humana por excelência e fonte de saúde para o ser humano, apesar da psicopatologia do trabalho. Além disso, eles propõem um modo de intervenção nos locais de trabalho baseado na própria vivência dos trabalhadores, incluindo aí a corporeidade como fator de transformação da organização do trabalho e de ressignificação deste pelos trabalhadores. Esse talvez seja o maior ponto de convergência dessas teorias com a proposta weiliana na atualidade, visto que enaltecem o agir humano no trabalho enquanto fonte de reconhecimento e de dignidade humana.

Diante do sofrimento operário decorrente da exploração e da submissão degradante às formas de organização do trabalho, esses pesquisadores buscam compreender os conflitos existentes nos postos de trabalho pela perspectiva dos próprios trabalhadores, considerando que eles podem superar os problemas de modo criativo e a partir de suas experiências individuais, sem desconsiderar que cada trabalhador pertence a uma coletividade. Observando a experiência operária vivenciada por Weil e sua busca por modos de transformação da opressão no trabalho, percebemos que sua proposta reside também na consideração da perspectiva dos

\footnotetext{
8 Para Simone Weil, nós significamos o mundo a partir do modo como o lemos. A pensadora identifica duas maneiras de mudar a maneira como lemos as sensações ( $1^{\circ}$ nível de leitura): pela força e pela aprendizagem, e essa mudança ocorre sobre a imaginação (Weil, 2008, p. 296). Em seu "Ensaio sobre a noção de leitura" (Weil, 2008), ela explica que a leitura do soldado ao ver outro homem em tempos de paz é diferente daquela realizada em tempos de guerra; eis um exemplo de como a força altera a leitura da realidade. Na paz, um soldado não lê um homem como inimigo quando ele está desarmado, mas na guerra isso poderá ocorrer pela leitura que o soldado faz do outro homem e por reagir a essa significação do outro como um inimigo a ser exterminado. $\mathrm{Na}$ guerra, o homem está submetido à força e, rebaixado por ela, lê sua derrota, tal como expresso no exemplo do soldado inimigo que se sente humilhado na guerra pelo estratagema criado pelo comandante. Porém, em seus Cadernos (Weil, 1997), a pensadora afirma que apenas a aprendizagem pode elevar o homem a outro nível de leitura $\left(2^{\circ}\right.$ e $3^{\circ}$ níveis de leitura) e, quem sabe, fazê-lo chegar à não leitura, compreendida pela pensadora como a completa integração (harmonia) do homem com a ordem do mundo.
} 


\section{pro.posıções \\ $e$-ISSN 1980-6248}

próprios trabalhadores, sendo eles a fonte de transformação dos modos de organização do trabalho.

A tensão entre o indivíduo e a coletividade, já abordada nos textos weilianos, é mais bem explicitada por Yves Clot (2010a) em seu modo de apropriação da teoria de Vygotsky. Nesse sentido, o trabalhador apropria-se de uma história, mas esta não consiste na reprodução de padrões socialmente impostos, e sim em uma apropriação feita pelo sujeito, que recria novas formas de agir em seu trabalho. Em termos weilianos, talvez possamos analisar essa liberação do ser humano em relação à sociedade por meio do conceito de leitura, visto que há sempre a possibilidade de o homem libertar-se da imposição de leituras impostas pela sociedade, mesmo daquelas que o encerram em um jogo de forças de dominação social e o alienam de seu próprio trabalho.

Dejours (2012), por sua vez, compreende essa tensão entre indivíduo e coletividade a partir do sofrimento resultante do confronto dos homens com a organização do trabalho e das estratégias de defesa desenvolvidas por eles para enfrentar situações reais de trabalho. Aqui também parece haver uma convergência com o pensamento weiliano, visto que a pensadora vivenciou em sua experiência operária a tensão existente entre o trabalho prescrito e o trabalho real, e denunciou essa cisão entre pensamento e ação na organização do trabalho.

Outro ponto de convergência entre nossos pensadores reside na noção de métier. Para Weil (1997), o métier é o saber-fazer que entra pelo corpo, tornando o ser humano flexível e habituado às ações solicitadas por seu trabalho. Nessa perspectiva do conhecimento corpóreo adquirido no métier, Dejours (2012), assim como Weil, reconhece que há uma inteligência prática anterior ao pensamento, e esta é expressa no corpo do trabalhador conforme os conceitos de "sexto sentido", na expressão de Dejours, e de "atenção", na expressão weiliana. Clot (2010a) também constata esse conhecimento adquirido através da apropriação corpórea dos gestos a serem realizados pelo trabalhador: estes não são apenas meras repetições, mas sim uma certa fluidez corporal expressa em seus gestos e no uso de seus instrumentos de trabalho. Isso talvez se assemelha às descrições weilianas acerca do corpo do ciclista experiente em comparação ao corpo do ciclista aprendiz, ou do marinheiro em seu barco em comparação ao passageiro durante uma tempestade. Nessas analogias do ciclista aprendiz e do ciclista experiente ao desviarem de um obstáculo, e do capitão e do passageiro ao lerem uma tempestade no mar, a diferença entre os pares não provém de um comando feito a si mesmo, nem de um simples 


\section{pro.posıções \\ $e$-ISSN 1980-6248}

desejo, nem de uma deliberação anterior, mas remonta à apropriação que tanto o ciclista quanto o marinheiro experientes possuem de seu próprio corpo, já submetido a um processo de habituação. É por isso que Simone Weil explica que o barco é extensão do corpo para o capitão, assim como a bicicleta para o ciclista, a bengala para o cego, as ferramentas para o trabalhador, o bico de pena para o escritor - e todos esses são exemplos de formas de leitura do mundo decorrentes de um processo de habituação. Essas formas de leitura são corpóreas e implicam uma íntima interação do homem com o mundo, como se fossem um só.

Contudo, não nos parece clara a relação entre métier e ausência de alienação no trabalho que parece estar implícita nas análises de Dejours e Clot. Ora, uma habilidade técnica que confere um conhecimento prático - fundado no sentir, e não no pensamento - refere-se a uma expertise do trabalhador para solucionar problemas em seu trabalho. Contudo, em que medida essa engenhosidade capaz de conferir reconhecimento ao trabalhador está relacionada à ausência de alienação desse trabalhador em seu posto de trabalho? Isso, é claro, se considerarmos o termo "alienação" como o não reconhecimento de si próprio naquilo que se faz. O que queremos dizer é que excelentes profissionais, que dominam o métier, podem não encontrar sentido no seu próprio fazer, mesmo que sejam reconhecidos pelos outros profissionais e sejam bem remunerados por seu trabalho.

Conceitualmente há uma diferença entre os pressupostos teóricos que fundamentam essa relação homem-mundo no trabalho: para Simone Weil (2008), o modelo de ação humana próprio do trabalhador é aquele em que há a decreação do sujeito, cuja ação fundamenta-se na impessoalidade daquele que obedece à ordem do mundo. Já para Clot (2010a) e Dejours (2012), o modelo que fundamenta a saída da alienação do trabalhador e reorganiza o trabalho consiste no esforço do sujeito para conquistar sua identidade, o que remete à noção de sujeito relacionada ao ego. Apesar dessa distância, ainda parece ser possível articular o pensamento de Weil ao de Clot e Dejours, pois a pensadora não nega toda a expertise do trabalhador presente nos gestos de seu trabalho e o quanto esse conhecimento inscrito no corpo caracteriza o próprio trabalho (métier).

Apesar disso, vale ressaltar que etimologicamente a palavra métier esteve ligada ao vocábulo latino ministerium, ou seja, remetia, no século XIII, à função de servidor no sentido religioso e foi, inclusive, equiparado à mysterium por sua dimensão sagrada, cultivada em ritos e celebrações. Apesar da acepção religiosa, esse vocábulo sofreu um processo de secularização, 


\section{pro.posıções \\ $e$-ISSN 1980-6248}

associando-se ao exercício de uma profissão ou de uma arte. Entre os séculos XV e XVI, o termo passou a designar os artesãos e, posteriormente, os trabalhadores; já no século XVII, foi frequente seu uso para referir algo ou alguém que é útil, indispensável (Frétigné, 2008, p. 130).

Nessa breve descrição etimológica, talvez possamos compreender que Simone Weil aproxima o trabalho da noção religiosa de métier, visto que o ser humano se coloca a serviço do outro em seu trabalho; ele se faz carne no trabalho e se oferece ao outro nessa ação, tal como o evento crístico da crucificação. Aqui encontramos uma distância e uma marca da singularidade do pensamento weiliano em relação à psicologia do trabalho, pois para a pensadora francesa o trabalho não apenas tem uma função psicológica privilegiada, mas possui uma função propriamente espiritual. Nessa relação espiritual do ser humano com seu trabalho se encontra uma nova maneira de o ser humano vivenciar sua ação no mundo. Na compreensão weiliana, essa relação não consiste simplesmente na resolução de conflitos ou no encontro de um sentido ou de uma finalidade no trabalho (dimensão psicológica, própria do ego), mas sim na compreensão de que o trabalho é uma mediação entre o ser humano e o transcendente, que não tem uma finalidade no mundo. Isso não significa a aceitação de condições degradantes de trabalho, mas confere ao trabalho uma perspectiva de doação, de obediência e de integração com os outros cujo fim não é a obtenção de prazer, status social ou ganho financeiro. Em termos weilianos, o sentido do trabalho é o próprio trabalhar, é agir com atenção plena, é fazer bem aquilo que não pode ser feito de outro modo, visto que há uma harmonia entre o ritmo do ato executado e aquele da ordem do mundo.

Se há uma convergência de Dejours e Clot com o pensamento de Weil que nos permite assinalar uma possibilidade de vivenciar a proposta weiliana no trabalho atual, esta se revela na atenção conferida pelos pesquisadores contemporâneos ao corpo do trabalhador e ao conhecimento sensível nele inscrito, que muito ultrapassa as prescrições de tarefas presentes em alguns modelos de gestão organizacional e permite uma experiência sensível do mundo no corpo em trabalho. Para melhor explicitar essa consideração sobre o corpo no trabalho, faremos referência a seguir à importância da corporeidade no ensino, defendida por Dreyfus, e à importância da prática da atenção como um método a ser utilizado nos postos de trabalho.

O filósofo norte-americano Hubert Dreyfus, professor da Universidade de Berkeley, foi influenciado pela tradição fenomenológica e existencialista. Em sua obra Sobre a internet (Dreyfus, 2009), ele investigou as causas do fracasso do modelo de aprendizagem a distância, enfatizando 


\section{pro.posıções \\ $e$-ISSN 1980-6248}

que a corporeidade é fundamental para a aprendizagem e que o ensino virtual não oferece a possibilidade de termos experiências encarnadas no mundo, considerando-se que não basta apenas a aquisição de conhecimentos teóricos. Concordamos com Dreyfus (2009) ao afirmar que:

nossa forma de vida é organizada por e para seres encarnados como nós: criaturas com corpos que têm mãos e pés, interiores e exteriores; que têm que se equilibrar em um campo gravitacional; que avançam mais facilmente do que se movem para trás; que se cansam; que têm que se aproximar objetos atravessando o espaço intermediário, superando obstáculos à medida que avançam etc. (p. 19)

Enquanto seres corpóreos, dependemos de nossa experiência situada no mundo, que é marcada por nossa configuração corporal, incluindo aí nossas emoções e humores. Isso nos permite conferir sentido às coisas, integrando-nos ao mundo e estabelecendo relações de confiança com os outros (Dreyfus, 2009). A aprendizagem, para Dreyfus, possui como fundamento não apenas o envolvimento racional, mas também a experiência encarnada do aprendiz, que pode alcançar um grau máximo de habilidade denominado por ele de expertise? Para tanto, Hubert Dreyfus e Stuart Dreyfus (2005) enumeram cinco estágios de desenvolvimento das habilidades, usando como exemplo a aprendizagem das habilidades requeridas para dirigir um automóvel ${ }^{10}$.

O primeiro estágio é o do novato, em que há uma aprendizagem formal dos processos envolvidos na direção de um veículo, incluindo os procedimentos e as características do automóvel, bem como as regras de direção em uma via. Assim, o iniciante deverá reconhecer cada uma delas e saber quando utilizá-las.

No segundo estágio, o aprendiz iniciante é capaz não apenas de reconhecer e aplicar as regras, mas descobre que a sua performance dependerá do contexto no qual ele trafega. Um exemplo seria a experiência de que seu controle de embreagem varia na subida de uma rua íngreme ou se muitos passageiros estiverem em seu veículo.

O terceiro estágio, por sua vez, consiste no desenvolvimento de uma competência em que o aprendiz é capaz de selecionar previamente aspectos relevantes para direcionar sua ação,

\footnotetext{
9 Optamos por não traduzir o termo inglês expertise por considerar ser uma palavra cujo sentido é compreendido em português e menos problemático que sua tradução por "competência" ou "perícia".

$10 \mathrm{Na}$ primeira edição de sua obra Sobre a internet, em 2001, Dreyfus (2009) enumerou sete estágios do desenvolvimento das habilidades; contudo, em um artigo de 2005, Hubert Dreyfus e Stuart Dreyfus sintetizam esses estágios em cinco níveis, que serão por nós explicitados para a compreensão de seu pensamento.
} 


\section{pro.posıções \\ $e$-ISSN 1980-6248}

o que torna sua tomada de decisão mais fácil. Nesse estágio, os autores alertam que há um grande envolvimento emocional do aprendiz, e quanto maior for sua capacidade de aceitação dos erros e dos acertos em suas escolhas, maior será o desenvolvimento de sua habilidade. Ao contrário disso, "a resistência ao envolvimento e ao risco leva à estagnação e, por fim, ao tédio e ao retrocesso" (Dreyfus \& Dreyfus, 2005, p. 785) no desenvolvimento das habilidades, pois é preciso uma flexibilidade para agir. No exemplo da aprendizagem da direção de um veículo, esta corresponderia à habilidade de determinar a velocidade para realizar uma curva acentuada.

O quarto estágio é marcado pela proficiência com que o aprendiz realiza sua ação. Esta se deve ao fato de a experiência já ter sido incorporada por uma via não teórica, em que as reações intuitivas substituem as respostas raciocinadas. Seria o estágio próprio à ação habitual, realizada facilmente e com o mínimo de estresse, tal como dirigir um veículo durante uma tempestade. Nesse estágio, o aprendiz percebe o que precisa ser feito, mas ainda decide racionalmente o modo como irá agir.

Por fim, temos o quinto estágio, marcado pela expertise, em que o aprendiz não apenas observa o que precisa ser feito, mas reconhece imediatamente o que deve fazer, agindo de modo intuitivo e imediato diante de uma situação. Esse estágio representa o desenvolvimento máximo da habilidade, pois o que deve ser feito simplesmente é feito, sem que se recorra às regras racionalmente formalizadas dos estágios anteriores. Hubert Dreyfus e Stuart Dreyfus (2005, p. 788) associam esse estágio à ação do homem de sabedoria prática descrito por Aristóteles em sua Ética nicomaqueia, visto que ele imediatamente faz a coisa apropriada, no momento apropriado e de forma adequada. Os autores norte-americanos explicam que normalmente o expert não calcula, não resolve problemas, nem mesmo pensa em sua ação, mas apenas age. Isso porque nenhuma quantidade de regras e fatos pode capturar o conhecimento que o expert tem quando nele estão armazenadas experiências de milhares de situações reais, que foram vivenciadas.

Hubert Dreyfus e Stuart Dreyfus (2005) também alertam para o fato de que a natureza cada vez mais burocrática da sociedade pode levar à perda dessa experiência intuitiva presente naqueles com expertise devido a uma hipervalorização da racionalidade científica. Desse estudo dos estágios de formação das habilidades, os autores concluem que, para que elas sejam desenvolvidas, não basta apenas serem compreendidas como interiorização de regras. Isso porque o desempenho baseado em regras levaria apenas até o terceiro estágio do 


\section{pro.posições \\ $e$-ISSN 1980-6248}

desenvolvimento, o da competência. Eles ainda concluem que a determinação de regras infalíveis para o aprendiz não leva à prevenção de erros, visto que há uma flexibilidade das ações presente na pessoa hábil. Daí os autores (Dreyfus \& Dreyfus, 2005, p. 791) encerrarem sua análise enfatizando a importância do julgamento intuitivo no exercício das profissões, que não devem se pautar apenas e prioritariamente na deliberação calculista.

A descrição dos estágios de desenvolvimento de habilidades feita por Hubert e Stuart Dreyfus (2005) parece convergir para a compreensão weiliana de leitura, visto que esses pensadores enfatizam o modo pelo qual o corpo se apropria do mundo e estabelece com ele uma relação harmoniosa. O corpo habituado realiza a ação não agente, para Weil (1997), e se expressa, de acordo com Dreyfus (2009), como se tem de agir, ou seja, nos dois pensadores o corpo torna-se fluido e obediente às solicitações que surgem de sua experiência no mundo.

Os pensadores ainda parecem se assemelhar nas críticas ao suposto saber teórico e burocratizado presente em nossa sociedade, que leva à negação da experiência vivida. Encontramos essa mesma crítica nos textos de Clot (2010a) e Dejours (2012) quando se referem à ergonomia de cunho positivista que prescreve um conjunto de procedimentos a serem executados pelos trabalhadores como forma de prevenção de acidentes no trabalho. Considerando, por exemplo, a proposta weiliana de ensinar geometria aos operários, percebemos que esse ensino visava diminuir a distância existente em sua época entre o conhecimento teórico dos engenheiros e o conhecimento técnico dos operários. Nesse sentido, a geometria entraria como um saber teórico-prático para o operário, visto ele já ter esse conhecimento geométrico em seus movimentos corporais no trabalho, mesmo que não soubesse racionalmente disso.

\section{Considerações finais}

Procuramos articular o pensamento weiliano às propostas da psicologia do trabalho expressas por Yves Clot e Christophe Dejours. Isso nos levou ao reconhecimento de que a pensadora, já nos anos 1930, compreendeu a importância de se considerar a centralidade do trabalho na vida humana e o modo como o corpo do trabalhador é fonte de conhecimento, expressando nos gestos de seu ofício toda a habilidade que caracteriza o métier. Hubert Dreyfus e Stuart Dreyfus, por sua vez, nos auxiliaram a compreender, a partir do modelo 


\section{pro.posıções

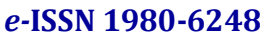

http://dx.doi.org/10.1590/1980-6248-2018-0063

fenomenológico, de que maneira se desenvolvem as habilidades e de que modo elas se expressam no corpo do expert. Sua análise permitiu articular o pensamento de Simone Weil acerca da leitura e do processo de habituação do corpo em trabalho com as características próprias da expertise.

As analogias corporais presentes nos textos weilianos também nos auxiliam a compreender de que modo a pensadora aproxima sua concepção de corpo em trabalho da noção de experiência intuitiva referida por Hubert e Stuart Dreyfus. A expertise enquanto grau máximo de habilidade é expressa nas analogias weilianas do marinheiro, que lê os perigos da tempestade nos movimentos de seu barco, ou do ciclista experiente, que lê os obstáculos a serem contornados. Em nenhuma dessas experiências parece haver um processo racional de deliberação anterior à leitura, mas sim uma fluidez corporal capaz de relacionar-se harmoniosamente com o mundo e compreender intuitivamente as demandas que lhe são feitas. Nesse aspecto, talvez seja possível articular a importância da atenção, para Simone Weil, à habilidade do expert, apresentada por Hubert e Stuart Dreyfus, pois nessa habilidade há uma qualidade de atenção que faz com que o trabalhador esteja apto para responder às demandas que lhe forem solicitadas, e seu corpo reage imediatamente a elas, visto já ter encarnado um repertório de conhecimentos sensíveis.

\section{Referências}

Brasil. (n.d.). Base de dados bistóricos da Previdência Social (2005-2013). Recuperado de http://www3.dataprev.gov.br/temp/DACT01 consulta79589775.htm

Chenavier, R. (1998). Civilização do trabalho ou civilização do lazer? Estudos Avançados, 12(32), $187-211$

Chenavier, R. (2001). Simone Weil: Une philosophie du travail. Paris: duCerf.

Clot, Y. (2006). Entrevista: Yves Clot. Cadernos de Psicologia Social do Trabalho, 9(2), 99-107. Recuperado de http://pepsic.bvsalud.org/pdf/cpst/v9n2/v9n2a08.pdf

Clot, Y. (2010a). Trabalho e poder de agir (G. J. F. Teixeira, \& M. M. Z. Vianna, trads.). Belo Horizonte: Fabrefactum.

Dejours, C., \& Gernet, I. (2012). Psychopathologie du travail. Paris: Elsevier Masson. 


\section{pro.posıções \\ $e$-ISSN 1980-6248}

http://dx.doi.org/10.1590/1980-6248-2018-0063

Dreyfus, H. L. (2009). On the internet (2a ed.). New York: Routledge.

Dreyfus, H. L., \& Dreyfus, S. E. (2005). Peripheral vision: Expertise in real world contexts. Organization Studies, 26(5), 779-792.

Frétigné, C. (2008). Le métier: Un analyseur des transformartions des mondes du travail. Recherche et Formation, 57, 129-139.

França, A. C. L., \& Rodrigues, A. L. (2005). Stress e trabalho: Uma abordagem psicossomática (4a ed.). São Paulo: Atlas.

Kühn, R. (2003). Primauté et dialectique du Bien: La critique de Marx par Simone Weil. Cabiers Simone Weil, 26(1), 51-87.

Sparling, R. (2012). Theory and praxis: Simone Weil and Marx on the dignity of labor. The Review of Politics, 74(1), 87-107.

Svartman, B. P. (2010). Trabalho e desenraizamento operário: Um estudo de depoimentos sobre a vida na fábrica. Tese de Doutorado, Universidade de São Paulo, São Paulo.

Weil, S. (1964). La condition ouvrière. Paris: Gallimard.

Weil, S. (1988a). Euvres complètes I: Premiers écrits philosophiques. Paris: Gallimard.

Weil, S. (1988b). Euvres complètes II: Écrits historiques et politiques. L'engagement syndical (1927 - juillet 1934) (Vol. 1). Paris: Gallimard.

Weil, S. (1991). CEuvres complètes II: Écrits historiques et politiques. L'expérience ouvrière et l'adieu à la révolution (juillet 1934 - juin 1937) (Vol. 2). Paris: Gallimard.

Weil, S. (1997). CEuvres complètes VI: Cahiers (septembre 1941 - féurier 1942) (Vol. 2). Paris: Gallimard.

Weil, S. (2008). Euvres complètes IV: Écrits de Marseille (1940-1942) (Vol. 1). Paris: Gallimard.

\section{Referências consultadas}

Chenavier, R. (2014). Marx dépassé « au-dedans de sa pensée ». In E. Gabellieri, \& F. L’Yvonnet (Orgs.), Cabier de L’Herne: Vol. 105. Simone Weil (pp. 243-248). Paris: L’Herne.

Clot, Y. (2007). A função psicológica do trabalbo (A. Sobral, trad., 2a ed.). Petrópolis: Vozes. 


\section{pro.posições}

http://dx.doi.org/10.1590/1980-6248-2018-0063

\section{$e$-ISSN 1980-6248}

Clot, Y. (2008). Le travail sans l'homme? Pour une psychologie des milieux de travail et de vie. Paris: La Découverte.

Clot, Y. (2010b). Le travail à cæur. Pour en finir avec les risques psychosociaux. Paris: La Découverte.

Submetido à avaliação em 19 de junho de 2018; revisado em 3 de setembro de 2018; aceito para publicação em 19 de setembro de 2018. 